\title{
Functional Alarming and Information Retrieval
}

\section{Goodstein, L. P.}

Publication date:

1985

\section{Document Version}

Publisher's PDF, also known as Version of record

Link back to DTU Orbit

\section{Citation (APA):}

Goodstein, L. P. (1985). Functional Alarming and Information Retrieval. Risø National Laboratory. Risø-M No. 2511

\section{General rights}

Copyright and moral rights for the publications made accessible in the public portal are retained by the authors and/or other copyright owners and it is a condition of accessing publications that users recognise and abide by the legal requirements associated with these rights.

- Users may download and print one copy of any publication from the public portal for the purpose of private study or research.

- You may not further distribute the material or use it for any profit-making activity or commercial gain

- You may freely distribute the URL identifying the publication in the public portal

If you believe that this document breaches copyright please contact us providing details, and we will remove access to the work immediately and investigate your claim. 
RIS(Q)

\section{Functional Alarming and Information Retrieval}

L. P. Goodstein

Ris $\varnothing$ National Laboratory, DK-4000 Roskilde, Denmark August 1985 
RIS $\emptyset-M-2511$

FUNCTIONAL ALARMING AND INFORMATION RETRIEVAL

L.P.Goodstein

Abstract. This paper deals with two facets of the design and efficient utilisation by operating personnel of computer-based interfaces for monitoring and the supervisory control of complex industrial systems - e.g., power stations, chemical plants, etc. These are alarming and information retrieval both of which are extremely sensitive to computerisation. For example, the advent of computers for display requires that some means of assuring easy and rapid access to large amounts of relevant stored information be found. In this paper, alarming and information retrieval are linked together through a multilevel functional description of the target plant. This representation serves as a framework for structuring the access to information as well as defining associated "alarms" at the various descriptive levels. Particular attention is paid to the level where mass and energy flows and balances are relevant. It is shown that the number of alarms here is reduced considerably while information about content and interrelationships is enhanced - which at the same time eases the retrieval problem.

INIS DEScriptors: ALARM SYSTEMS; CONTROL ROOMS; DIAGNOSIS; DISPLAY DEVICES; FLOW MODELS; FUNCTIONAL ANALYSIS; HUMAN FACTORS; INDUSTRIAL PLANTS; INFORMATION NEEDS; INFORMATION RETRIEVAL; MAN-MACHINE SYSTEMS; MONITORING; POWER PLANTS.

Risø National Laboratory, DK-4000 Roskilde, Denmark 
TABLE OF CONTENTS

Page

INTRODUCTION

5

THE FUNCTIONAL APPROACH $\ldots \ldots \ldots \ldots \ldots \ldots \ldots \ldots \ldots \ldots \ldots \ldots \ldots \ldots \ldots$

FUNCTIONAL ALARM DISPLAY $\ldots \ldots \ldots \ldots \ldots \ldots \ldots \ldots \ldots \ldots \ldots \ldots \ldots$

INFORMATION RETRIEVAL $\ldots \ldots \ldots \ldots \ldots \ldots \ldots \ldots \ldots \ldots \ldots \ldots \ldots$

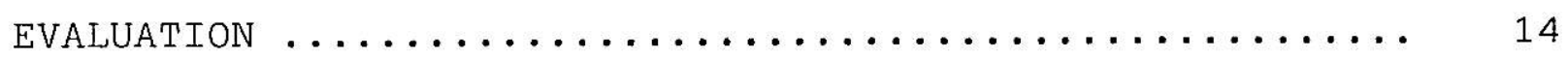

CONCLUDING REMARKS $\ldots \ldots \ldots \ldots \ldots \ldots \ldots \ldots \ldots \ldots \ldots \ldots \ldots \ldots \ldots$

ACKNOWLEDGEMENT $\ldots \ldots \ldots \ldots \ldots \ldots \ldots \ldots \ldots \ldots \ldots \ldots \ldots \ldots \ldots$

REFERENCES $\ldots \ldots \ldots \ldots \ldots \ldots \ldots \ldots \ldots \ldots \ldots \ldots \ldots \ldots \ldots \ldots \ldots \ldots \ldots \ldots$ 
INTRODUCTION

This paper deals with two facets of the design and efficient utilization by operating personnel of computer-based interfaces for monitoring and the supervisory control of complex systems e.g., power stations, chemical plants, etc.

The first, alarming, has been a perennial point for discussion ever since its original aim of providing assistance in process monitoring through the "principle of exception" has been considerably compromised by the sheer weight of numbers. Traditional annunciator approaches force operators in realistic situations to employ complex scanning and mental processing in order to sort out the many alarms and prioritize their responses. This has proved to be difficult. The advent of the computer has in one way worsened the situation in that whatever advantage could be connected with a pattern perception based on specific geographical locations for each alarm on a wall panel has been lost through the use of alarm lists on VDU's.

As this writer pointed out in an earlier paper (1), "It is safe to say that current alarm systems are quite "contaminated" because of the non-use of any method which reflects a systematic modelling of the plant by the designer as the basis for alarm selection. Instead, other less objective criteria seem to apply so that, e.g., in modern nuclear plants, there exist literally thousands of "alarms". In response to a recognition that this indeed is intolerable, considerable efforts are being devoted to alarm filtering, conditioning and analysis while, however, retaining the basic approach of attempting to capture and display in essentially raw form the behaviour of thousands of bits of data reflecting system state at many levels of importance and urgency."

See also (2) - (5).

The second item, information retrieval, can perhaps seem misplaced, but in fact, it is quite relevant today as a direct consequence of the widespread use of computers with VDU's having restricted viewing areas. Perhaps when the era of the economical remote-controlled wall panel arrives, this situation will be eased. However, until then, designers are and will be faced with the problem of making sequential accesses to an extensive library of process information easy and efficient for the users without distorting thought processes, disrupting good search strategies and/or overloading memory. 
At first thought, these two problems may seem to be somewhat unrelated. However, when one considers the role of alarming i.e., to alert the operator and

a) in traditional control rooms, point him to the proper subpanel (s)

b) with VDU's, help him select the appropriate display out of the available set,

it is clear that the opposite is true. Recent work at Risø has pointed to the beginnings of an integrated approach to information displays which can serve to alleviate both difficulties. This is based on various studies on diagnosis, system representation, human information processing which have been reported elsewhere. See, e.g., (6) and (7).

THE FUNCTIONAL APPROACH

In dealing with complex systems, it is commonplace for humans to attempt to reformulate or restructure a problem so that it becomes more amenable to solution. In our work, we have characterized the related problem space as being two-dimensional with the axes whole-part and abstract-concrete, as shown in Fig. 1 . Whole-part variations refer to changes in the "field of view" which so to speak permit the problem-solver to "pan and zoom" within a system map in order to be able to consider total system, subsystem, equipment or single components through varying mesh sizes. Abstract-concrete variations refer to human inclinations to speculate about the same system, subsystem, etc. in different ways - e.g., as indicated on Fig. 1, about purpose, function or physical implementation.

We place great weight on this characterization of the problem space and especially its implications for the display and control interface. Within the context of this paper, it will be appropriate to concentrate on the functional aspects and their role in alarming and information retrieval. See the references for a broader discussion. 
VARYING NEEDS FOR INFORMATION

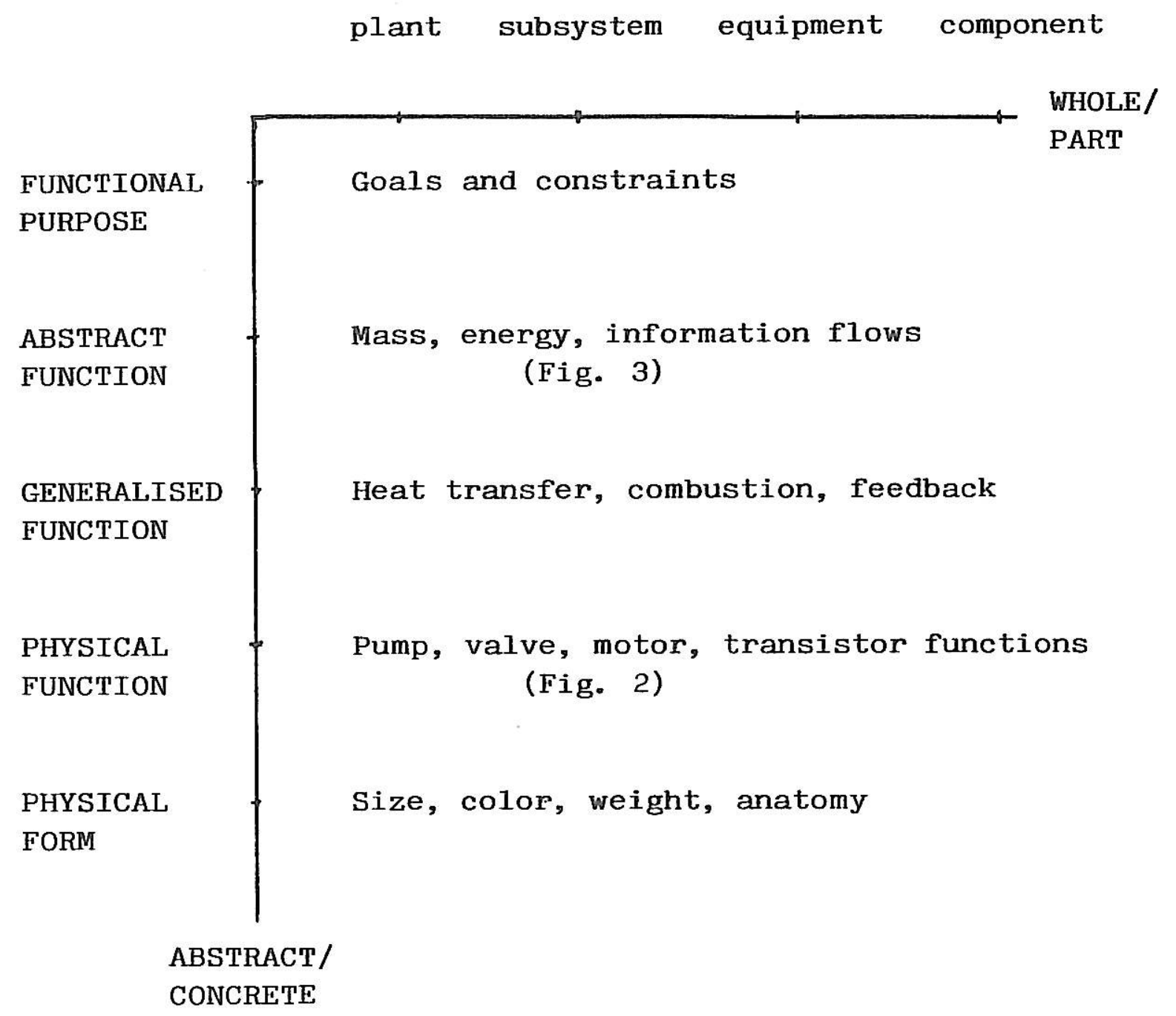

Figure 1 
As an example of the differences in representation along the abstract-concrete dimension, Figs. 2 and 3 illustrate the same (very simplified) Pressurized Water Reactor (PWR) plant. Fig. 2 resembles a typical process diagram and corresponds in our classification to a "physical functional" depiction in terms of the available physical resources or objects - such as pumps, valves, pipes - which have given, familiar functional properties.

On the other hand, although perhaps not evident at first glance, Fig. 3 depicts the same PWR expressed as a hierarchical network of - in terms of Fig. 1 - "abstract functions" resulting from a top-down functional identification and description in terms of mass and energy flows in the system. See (8) and (9) for a discussion of this modelling technique. Thus Fig. 3 indicates the top goals concerned with securing safe operation while assuring the availability of production.

For safety, the main concern is to maintain the various barriers against undesired releases while, for production, the chief interest lies in the efficient conversion and distribution of the source energy. Thus assuring the integrity of the primary and secondary systems requires adequate heat removal. To produce electricity requires a chain of energy transport and conversion elements. Both of these are similar in nature and thus place similar requirements on the lower level support functions. Thus these turn out to be not mutually exclusive so that smaller or larger bits of process can be involved in supporting more than one user function at the higher levels. Thus the structure indicates directly the connectiveness/interdependence among the functions necessary to achieve the top goals of safety and production.

As shown in the figure, each function has a goal set by its "user" functions, which leads to the definition of a control task for the function as well as a set of critical variables the state of which reflects whether the particular function is indeed meeting its goal(s). The values of these critical variables will in general require a data integration and transformation of the relevant "raw" process data into units which are consistent with the particular level of abstraction - in this case, the "abstract-functional", related to mass and energy. A running comparison of these computed variables with compatibly defined limit values leads directly to the idea of a functional alarm at the abstract-functional level. 


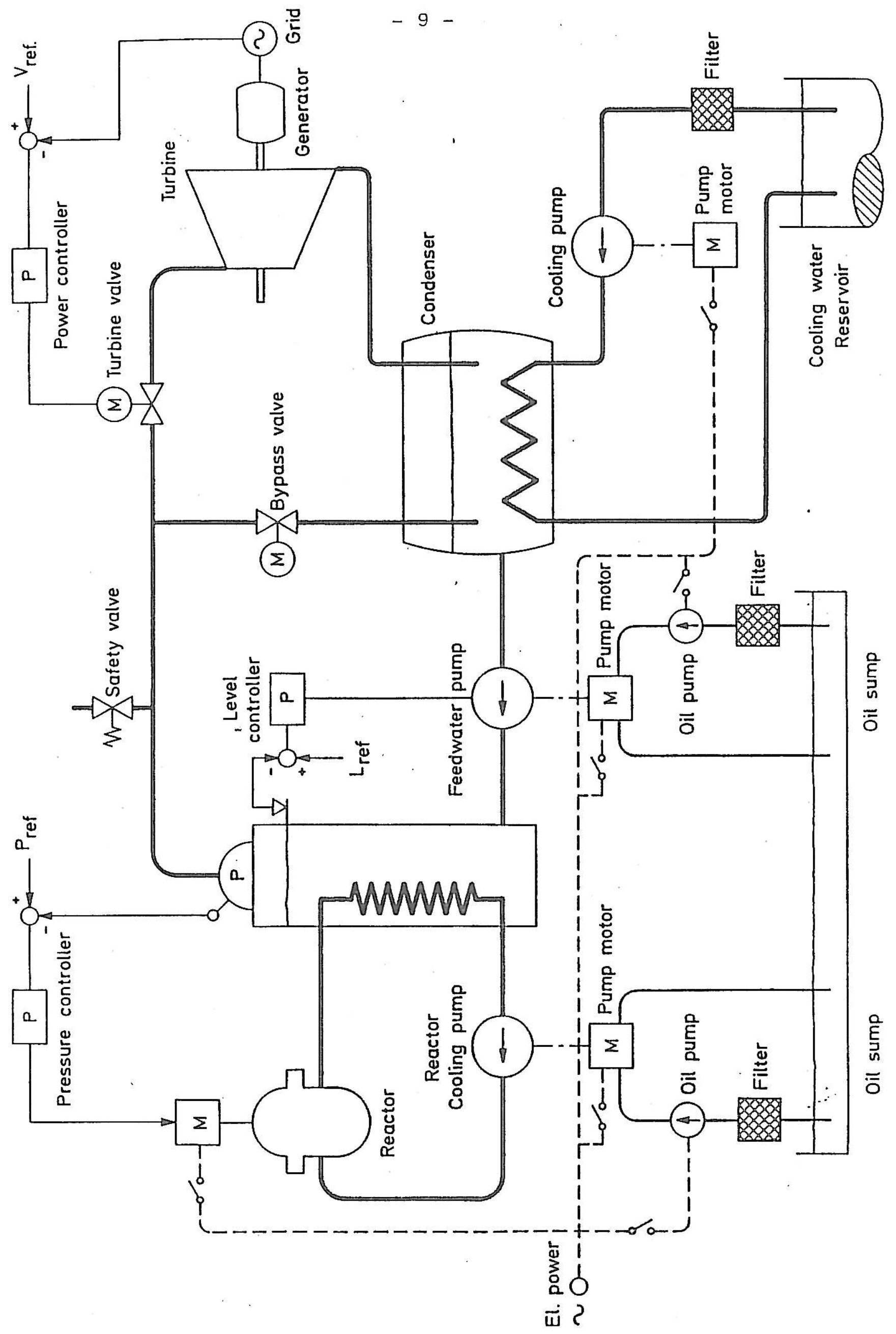




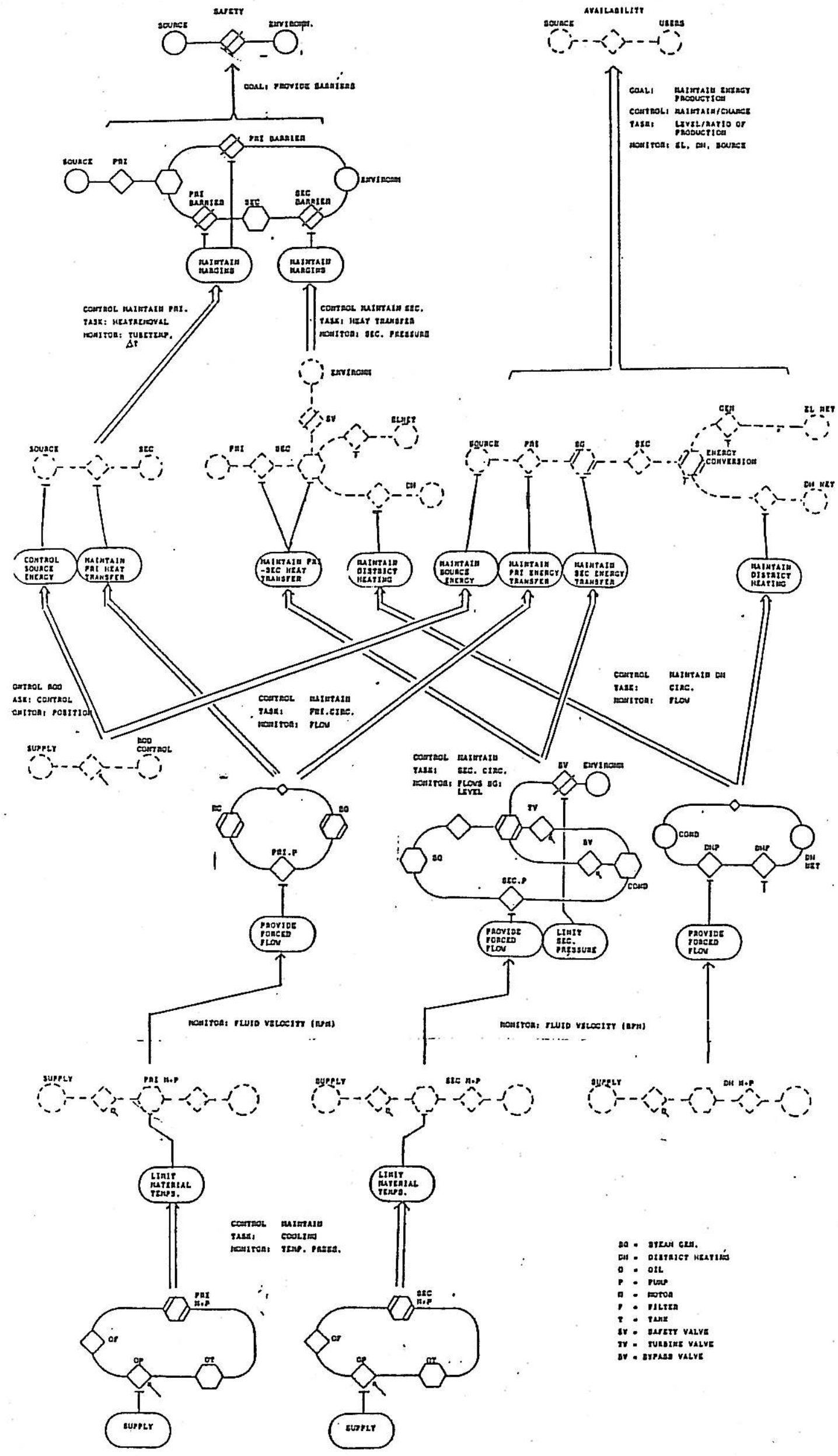

Figure 3 - An ABSTRACT-FUNCTIONAL REPRESENTATION 
The set of "abstract-functional" alarms will be far fewer in number than a traditional set (by a factor of hundreds for a nuclear power plant) and more global in juformation content. These are attributes which certainly are "friendlier" with respect to the operators' needs and capabilities in considering the cause, extent and potential effects of disturbances. It is certainly necessary that the operator be able to "see the forest for the trees", at least in the initial phases of a diagnosis, and the richer and more structured information set described here is a means for achieving that goal.

In a similar way, corresponding "alarms" and data transformations can be defined at the other levels of abstraction of Fig. 1 - including, of course, the traditional and familiar set at the level of "physical-function".

FUNCTIONAL ALARM DISPLAY

Fig. 4 illustrates a simple functional alarm display for the PWR plant shown in Figs. 2 and 3. A comparison of Figs. 3 and 4 will show that the annunciator areas A-P in Fig. 4 correspond to the functions on Fig. 3 and that they are interconnected together in the same way to form the same functional network. Thus Fig. 4 gives information on functional status via annunciator status (color, blink) as well as the relationships among functions to aid in understanding (a) the top-down allocation of functional requirements and (b) the bottom-up paths for the propagation of faults in the system.

In the examples shown on Fig. 4, 4a indicates a single alarm while $4 \mathrm{~b}$ is an example of a more complex disturbance. In fact, common-mode faults and/or multiple faults will usually lead to distinctive patterns and thereby have a reasonable chance of being detected.

Although Fig. 4 denotes each function by a letter within a square, an alternative of course would be to use a set of suitable icons, each of which in some easily recognizable way could reflect the purpose of the function - e.g., heat transfer, circulation, etc. 


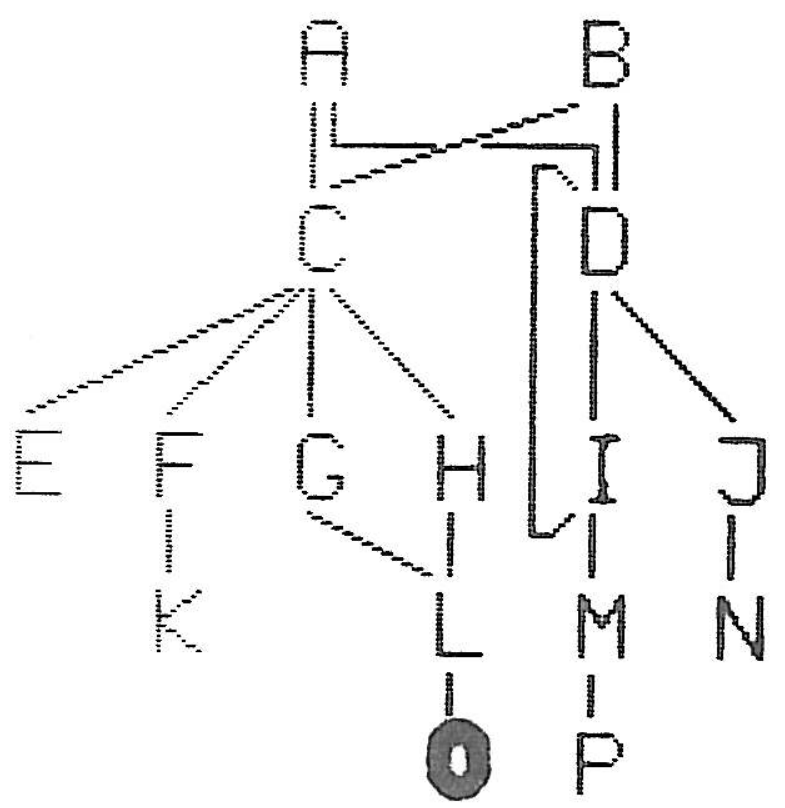

(a) Single Alarm

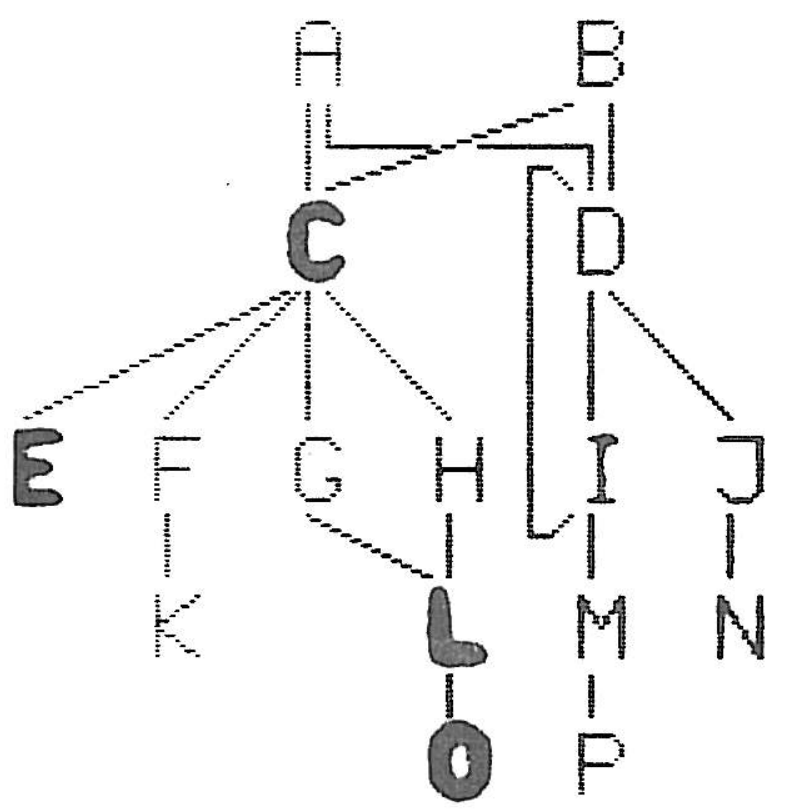

(b) More complex alarm pattern 
INFORMATION RETRIEVAL

In previous papers (10 and 11$)$, it was argued that this (almost) hierarchical arrangement of functional processes was a suitable framework on which to base a display-accessing mechanj.sm for the operators. It is important when monitoring overall goals and detecting and responding to system upsets to be able to proceed in an orderly and systematic way through a consistent set of information displays so as to be able to narrow in on the relevant process where an appropriate recovery can be made. It was suggested that, for each process, various "windows of information" should be made available which, to express it succinctly, would give the operator information on its WHY, WHAT and HOW. These windows would each correspond roughly to a location on the abstract-concrete axis to reflect goal, state, structure, implementation, manipulation, etc. in order to support possible alternate forms for operator thinking and decision making. See Fig.5 for a typical cluster of these windows.

This current paper reinforces the argument by suggesting that the functional alarm array also can serve simultaneously as an input display selection menu thus giving the operator a simple and direct display access via a selected function. Thus an ailing function will be signalled in the array and the operator, e.g., through a touch panel (or by other means), could respond directly by pointing at the signalling element (which of course acknowledges this) and the main window in the display cluster for the particular function would appear. Fig. 6 illustrates an example of this.

Advantages are that "dead ends" are avoided. Operators can always see where in the functional array they are currently looking. They have a permanent overview of the functional dependencies to help them search in the system while, at the same time, the array is continuously displaying an updated view of functional status in the system. As was pointed out earlier, multiple failures can also be easier to discern and deal with.

It must be recognized that each functional network is static in the sense that it is dependent on the current operating mode and thus will vary in structure - e.g., for full power, startup, shutdown, emergency modes, etc. This can be considered as an advantage compared to conventional single-level alarm systems which essentially are mode-independent and depend on the oper- 
ator to sort things out. In the functional approach, the displayed alarm and retrieval net will vary with operating mode (as determined by the operator and/or the computer) while transitions between operating modes will of course require additional displays to manage and give suitable feedback regarding the manual/automatic control actions which are required.

\section{EVALUATION}

The display examples used in this paper are taken from an experimental facility at our laboratory which is being used in conjunction with studies of human decision making in supervisory control. See (12). A number of experiments have been run using the functional alarm and retrieval concept as an integrated part of a display set for assistance in plant diagnosis. The PWR simulation comprised fifteen functions. The results are as yet preliminary and do not give any firm basis for comparing functional with conventional alarming. The experiment do indicate that users can learn to use the system as an aid in diagnostic searching but have some difficulties with relating a functional approach to their more equipment-oriented background. It is obvious that considerable training and practise are required.

It is relevant to point out that an actual nuclear plant would have three-to-four times as many functions; i.e., about 50-60, so that the design and implementation of a functional alarm and retrieval system would lead to a considerable reduction in the number compared to a conventional approach as well as a significant improvement in the organisation of the alarms and hence access to information.

CONCLUDING REMARKS

This paper has attempted to integrate the problems of alarms and information retrieval in a systematic approach to the design of information systems in the control room. This approach builds in part on a multi-level representation of the object plant 
LINKS TO USER WINDOW SETS
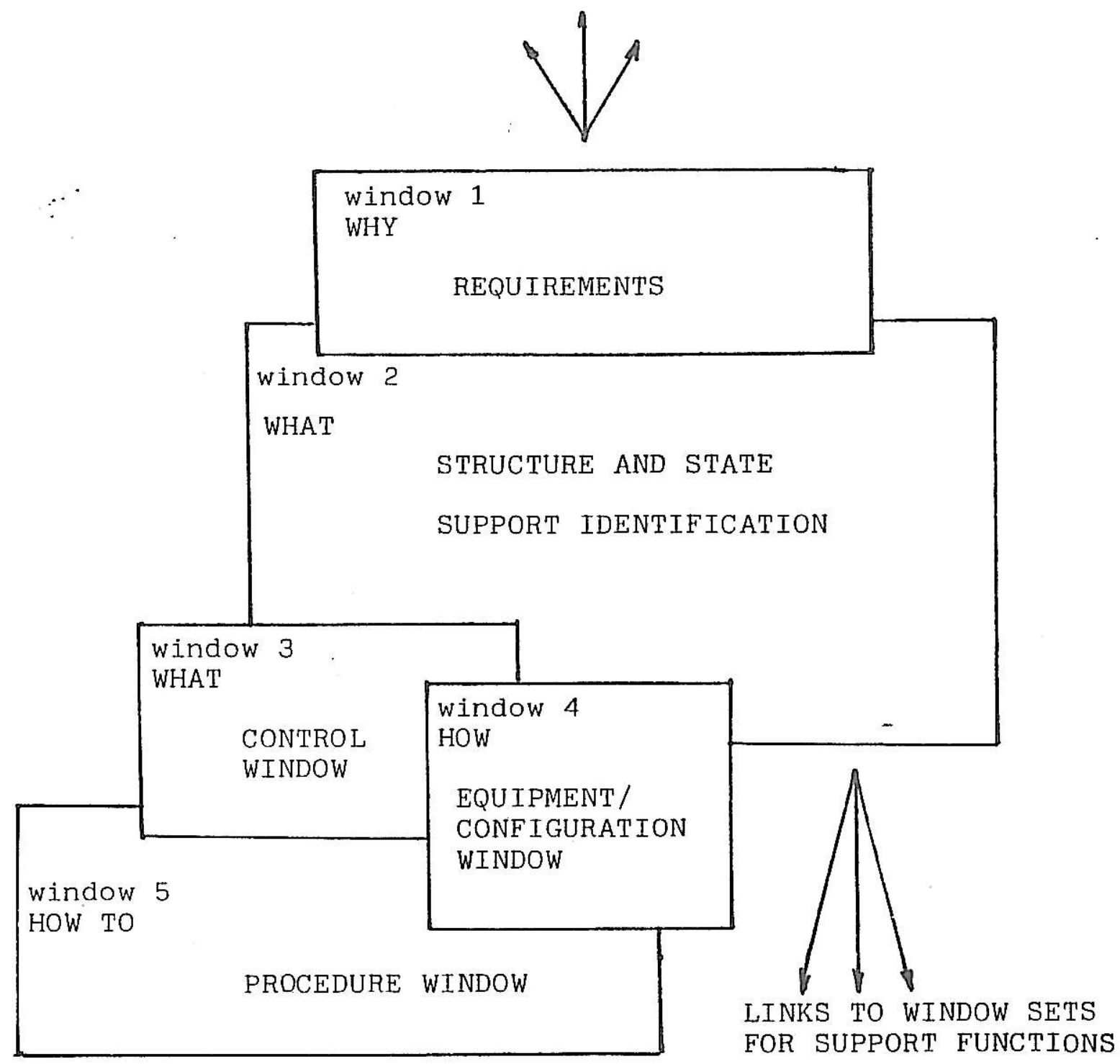

Figure 5 Multi-window Approach to information Display 
$C$ is the selected function for display

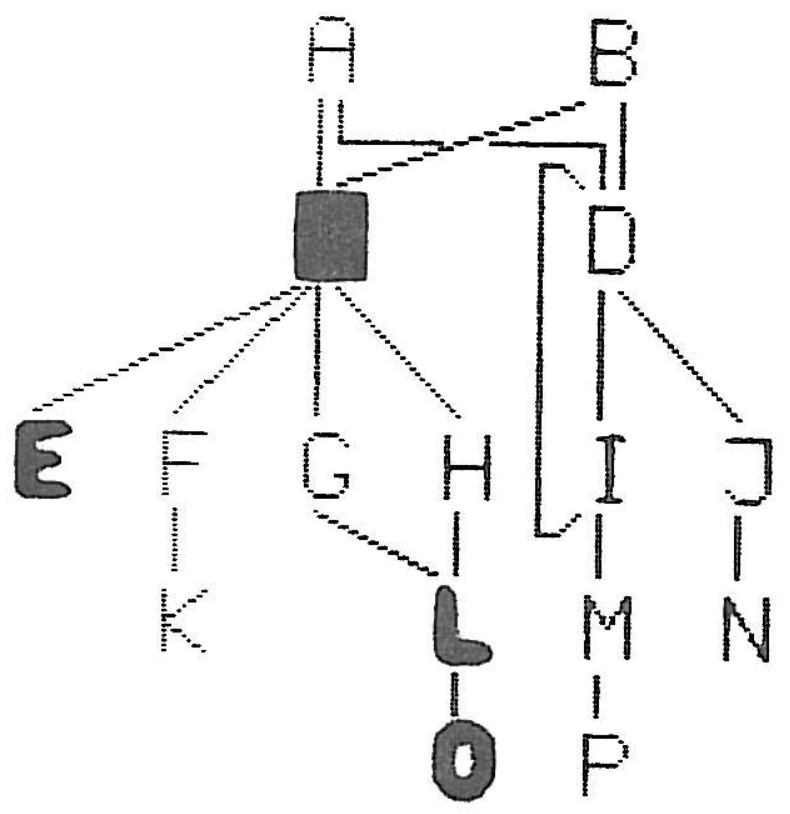

Functions $\mathrm{C}, \mathrm{E}, \mathrm{I}$ and $\mathrm{O}$ are alarming

Figure 6 Information Retrieval Through the Functional Array 
which, in turn, has important implications for the characterisation (and display) of the relevant information concerning the plant. Thus alarms also become multi-level when incorporated as an alerting function. This paper has concentrated on alarming at the abstract-functional level - corresponding to the fundamental mass and energy conditions in the plant system - to indicate the possibilities of achieving an information-rich and - importantly - a manageable set of alarms which can serve as signposts announcing deviations in the system functional network. At the same time, the functional representation at this level invites utilisation as an information access framework.

ACKNOWLEDGEMENT

This work was supported in part by the Nordic Council of Ministers.

REFERENCES

(1) Goodstein, L.P. (1981). Discriminative Display Support for Process Operators - in "Human Detection and Diagnosis of System Failures", J. Rasmussen and W. B. Rouse (Eds.), Plenum Publishing Co.

(2) Lees, F. (1983). Process Computer Alarm and Disturbance Analysis: Review of the state of the Art - Computers and Chemical Engineering - v.7 No.6 1983.

(3) Andow, P. K., Lees, F. P. (1974). Process Plant Alarms Systems: General Considerations - in Proceedings of the First International Symposium on Loss Prevention - The Hague, Holland.

(4) Andow, P. K. (1983). Improvement of Process Alarm Systems - in Eurochem 1983, Birmingham, UK. 
(5) Danchak, M. M. (1982). Alarms within Advanced Display Systems: Alternatives and Performance Measures NUREG/CR-2776 EG-2202.

(6) Rasmussen, J. and Lind, M. (1982). A Model of Human Decision Making in Complex. Systems and its Use for Design of System Control Strategies - in Proceedings of the American Control Conference, Arlington, Va.

(7) Rasmussen, J. (1984). Strategies for state Identification and Diagnosis in Supervisory Control Tasks and Design of Computer-based Support Systems - to be published in "Advances in Man-Machine Systems Research", Vol.1, W.B.Rouse (ed).

(8) Lind, M. (1981). The Use of Flow Models for Automated Plant Diagnosis, - in Rasmussen,J. and Rouse W.B. (Eds), Human Detection and Diagnosis of System Failures. Plenum Press, N.Y., 1981.

(9) Lind, M. (1982). Multilevel Flow Modelling of Process Plant for Diagnosis and Control - in Proceedings of International Meeting on Thermal Nuclear Reactor Safety - Chicago, U.S.A., August 29 - September 2, 1982.

(10) Goodstein, L. P. (1982). Computer-based Operating Aids - Proceedings of Design 82 Conference,Birmingham, England IChE Symposium Series 76.

(11) Goodstein, L. P. (1983). An Integrated Display Set for Process Operators - in Proceedings of IFAC/IFIP/IFORS /IEA Conference of Analysis, Design and Evaluation of Man-Machine Systems - Baden Baden, FRG; Pergamon Press.

(12) Goodstein, L. P., Hedegård, J., Højberg, K. S., Lind, M. (1983). The GNP Testbed for Operator Support Evaluation - in Proceedings of Third European Annual Conference on Human Decision Making and Manual Control Risø, Denmark. 


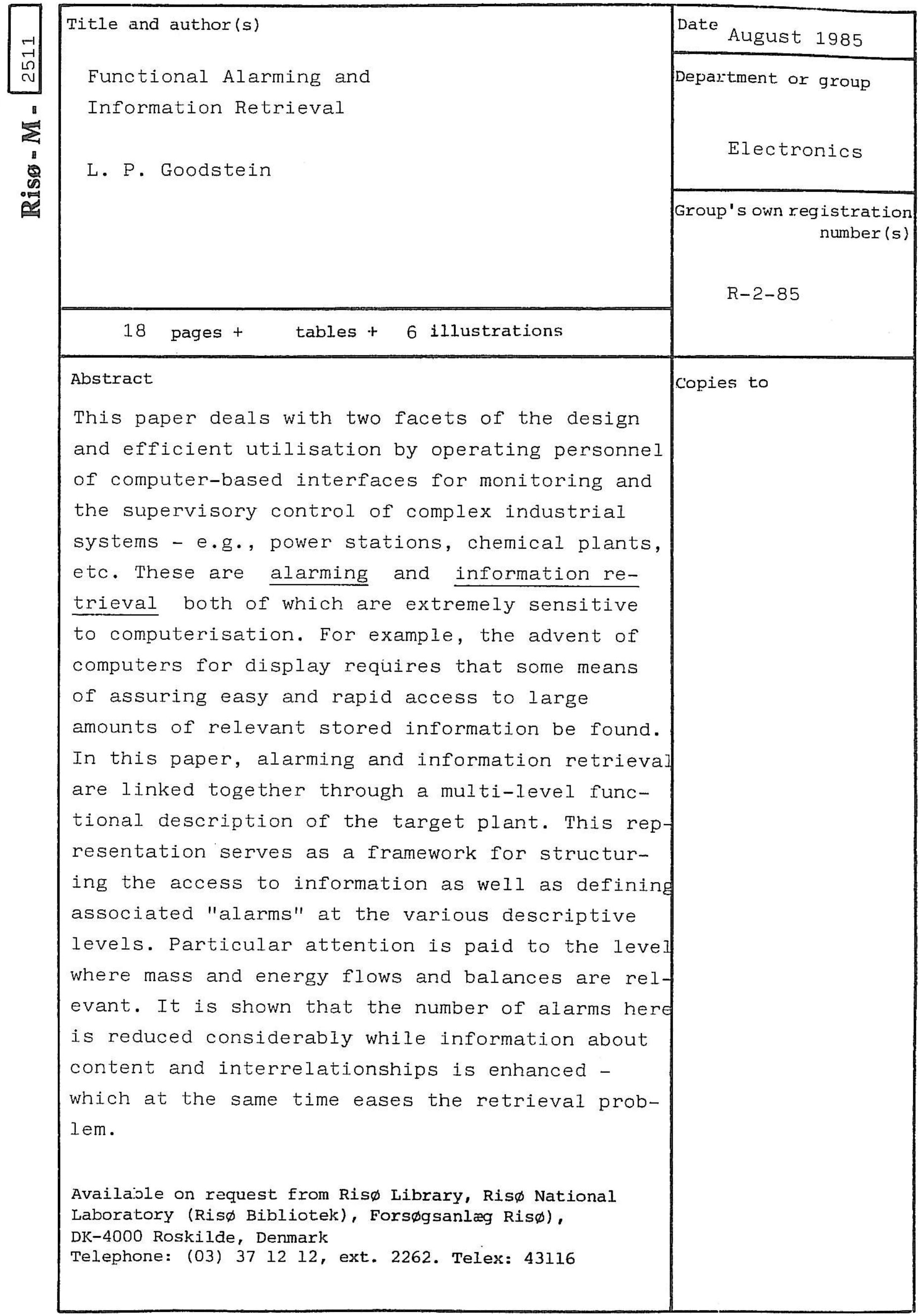


Available on request from.

Risø Library,

Risø National Laboratory, P. O. Box 49,

DK-4000 Roskilde, Denmark

Phone (02) 371212 ext.2262 